Check for updates

Cite this: RSC Adv., 2019, 9, 38345

Received 17th September 2019 Accepted 14th November 2019

DOI: 10.1039/c9ra07525a

rsc.li/rsc-advances

\section{Performance of graphite felt as a cathode and anode in the electro-Fenton process}

\begin{abstract}
Junfeng Li, (D) *a Dongbao Song, ${ }^{a}$ Keqing Du, ${ }^{a}$ Zhaoyang Wang ${ }^{\text {bcd }}$ and Chun Zhao ${ }^{\text {acd }}$
Choosing an electrode material with good performance and low cost is of great significance for the practical application of the electro-Fenton process. In this study, graphite felt was systematically studied to determine its application performance in an electro-Fenton system. The influence of operating parameters, $\mathrm{pH}$ and voltage, on the $\mathrm{H}_{2} \mathrm{O}_{2}$ yield and the evolution of iron ions was investigated, which helped to select the optimal parameter values. The removal rate of methylene blue was $97.8 \%$ after 20 min electrolysis under the conditions of $7 \mathrm{~V}$ voltage and $\mathrm{pH}$ 3. Inhibition experiments showed the graphite felt E-Fenton system mainly relied on the indirect oxidation of $\cdot \mathrm{OH}$ and the direct oxidation of the graphite felt anode to degrade the methylene blue. The graphite felt showed good stability as a cathode during repeated use, but the anode conductivity and catalytic performance were decreased, and the adsorption performance was enhanced. Finally, the graphite felt electrode was characterized by scanning electron microscopy (SEM), X-ray diffraction (XRD), Brunauer-Emmett-Teller (BET) and X-ray photoelectron spectroscopy (XPS) to preliminarily analyze the reason for the change in anode performance.
\end{abstract}

\section{Introduction}

In recent years, the electrochemical advanced oxidation process (EAOPS) has been developed for the prevention and remediation of environmental pollution, especially for water treatment. ${ }^{1}$ The core of EAOPs is a series of physical processes and chemical reactions to generate the hydroxyl radicals $(\cdot \mathrm{OH}) \cdot \cdot \mathrm{OH}$ has a strong oxidation potential $(2.87 \mathrm{~V})$, which is second only to $\mathrm{F}$ $(2.87 \mathrm{~V}) .^{2} \cdot \mathrm{OH}$ can oxidize the vast majority of organic pollutants in wastewater to $\mathrm{CO}_{2}, \mathrm{H}_{2} \mathrm{O}$ and inorganic ions. ${ }^{3}$ As a kind of environmentally friendly electrochemical advanced oxidation process, electro-Fenton (E-Fenton) technology is highly favoured to treat wastewater because of its advantages, such as high utilization rate of $\mathrm{H}_{2} \mathrm{O}_{2}$ and $\mathrm{Fe}^{2+}$, process cleaning, low sludge residue and low investment cost. ${ }^{4}$

$$
\begin{gathered}
\mathrm{O}_{2}+2 \mathrm{H}^{+}+2 \mathrm{e}^{-} \rightarrow \mathrm{H}_{2} \mathrm{O}_{2} \\
\mathrm{Fe}^{2+}+\mathrm{H}_{2} \mathrm{O}_{2} \rightarrow \mathrm{Fe}^{3+}+\cdot \mathrm{OH}+\mathrm{OH}^{-} \\
\mathrm{RH}+\cdot \mathrm{OH} \rightarrow \mathrm{H}_{2} \mathrm{O}+\cdot \mathrm{R} \cdots \mathrm{H}_{2} \mathrm{O}+\mathrm{CO}_{2} \\
\mathrm{Fe}^{3+}+\mathrm{e}^{-} \rightarrow \mathrm{Fe}^{2+}
\end{gathered}
$$

${ }^{a}$ College of Water Conservancy and Architecture Engineering, Shihezi University, Shihezi 832000, Xinjiang, China.E-mail: ljfshz@126.com; Tel: +86-152-9992-1362 ${ }^{b}$ College of Earth and Environmental Science, Lanzhou University, Lanzhou 730000 , PR China

${ }^{c}$ School of Urban Construction and Environmental Engineering, Chongqing University, Chongqing 400001, China

${ }^{d}$ Key Laboratory of the Three Gorges Reservoir Region's Eco-Environment, Ministry of Education, Chongqing University, Chongqing 400045, China
In the E-Fenton system, $\mathrm{O}_{2}$ can react with $\mathrm{H}^{+}$at the cathode to generate $\mathrm{H}_{2} \mathrm{O}_{2}$ (eqn (1)), and then $\mathrm{H}_{2} \mathrm{O}_{2}$ reacts with $\mathrm{Fe}^{2+}$ to produce the $\cdot \mathrm{OH}$ oxidizing organic pollutants (eqn (2) and (3)). ${ }^{5,6}$ Compared with traditional Fenton technology, one of the advantages of E-Fenton technology is to eliminate the trouble of adding $\mathrm{H}_{2} \mathrm{O}_{2}$ and avoiding the potential danger of $\mathrm{H}_{2} \mathrm{O}_{2}$ storage and transportation. ${ }^{7,8}$ Another advantage of E-Fenton technology is that $\mathrm{Fe}^{2+}$ can be regenerated at the cathode, which greatly reduces the production of iron sludge. ${ }^{9,10}$ It can be seen that studying the evolution of iron ions and the production of $\mathrm{H}_{2} \mathrm{O}_{2}$ are of great significance for further understanding and regulation of E-Fenton technology. $\mathrm{pH}$ and voltage are two important factors affecting the evolution of iron ions and the production of $\mathrm{H}_{2} \mathrm{O}_{2}$. However, people are more concerned with the effect of iron ion dosage, $\mathrm{pH}$ and voltage on the removal rate of pollutants, no further consideration is given to the effects of iron ions evolution and $\mathrm{H}_{2} \mathrm{O}_{2}$ production. ${ }^{11,12}$ There are also many scholars who regulate the production of $\mathrm{H}_{2} \mathrm{O}_{2}$, but their purpose is to maximize $\mathrm{H}_{2} \mathrm{O}_{2}$ production through technical regulation. ${ }^{\mathbf{1 3 , 1 4}}$ Therefore, the relationship between $\mathrm{H}_{2} \mathrm{O}_{2}$ production, iron ion evolution, and contaminant removal rate needs further study. In addition, choosing an electrode material with good performance is a problem that troubles the practical popularization of E-Fenton technology. ${ }^{15}$ Most of the anodes choose $\mathrm{Pt}, \mathrm{BDD}$, etc; however, they are rarely used for practical purposes because of their high cost. ${ }^{1,16}$ Since both $\mathrm{H}_{2} \mathrm{O}_{2}$ production and iron ion regeneration occur at the cathode, most people choose carbon-based three-dimensional electrode materials for the cathode, such as graphite felt, ${ }^{17}$ carbon felt, ${ }^{18}$ carbon sponges and activated carbon fibres. ${ }^{19,20}$ Some 
researchers have modified three-dimensional electrode materials to improve the application performance. For example, Ganiyu et al. used $\mathrm{Fe}^{\mathrm{II}} \mathrm{Fe}^{\mathrm{III}} \mathrm{LDH}$ modified carbon felt cathode to achieve efficient metronidazole removal over a wide $\mathrm{pH}$ range. ${ }^{21}$

Compared with two-dimensional electrodes, threedimensional electrodes have the advantages of counteracting the limitations of the low space-time yield and low normalized space velocity from electrochemical processes. $^{22}$ Some researchers also used three-dimensional electrode materials as anodes. For example, Yi et al. used activated carbon fiber as the anode to degrade the alizarin red S (ARS) dye, and believed that there is synergy between adsorption and electrochemical oxidation during electrolysis. ${ }^{23}$ Since the functions of the anode and the cathode are different in the E-Fenton system, the threedimensional electrode material as the cathode and the anode to construct the E-Fenton system to degrade the pollutants need to be further studied. However, there are few reports using threedimensional electrode materials as the cathode and anode in the E-Fenton system to degrade pollutants. Considering that the E-Fenton process is developed for long-term and large-scale applications, the stability of the electrode is important for determining the performance of the EF process. Zhou et al. evaluated the stability of anodized GF electrode for $p$ nitrophenol degradation in 10-times continuous runs, and the TOC removal efficiency decreased within $15 \%{ }^{24}$ However, the running time of these tests are not long enough. ${ }^{13}$ How to deal with these scrapped electrodes is another issue to consider after the electrodes lose their electrochemical properties, so a lot of repeated experiments are needed to determine the changes in their performance.

Therefore, this study selected three-dimensional electrode material graphite felt as the cathode and anode to degrade the methylene blue, graphite felt was systematically studied to determine its application performance in the electro-Fenton system. To highlight the influence of operating parameters, the evolution of the iron ions and the effects of voltage and $\mathrm{pH}$ on $\mathrm{H}_{2} \mathrm{O}_{2}$ production were studied. The experimental data of methylene blue degradation were fitted, and a kinetic model was established. The degradation mechanism for the graphite felt E-Fenton system was studied in detail. Finally, a repeated use experiment was carried out to determine the change of performance of the graphite felt electrode before and after use.

\section{Materials and methods}

\subsection{Materials}

Analytical grade methylene blue (7220-79-3, 99\%), methanol (67-56-1, 99.5\%), $\mathrm{FeSO}_{4} \cdot 7 \mathrm{H}_{2} \mathrm{O}$ (7782-63-0, >99\%) and $\mathrm{Na}_{2} \mathrm{SO}_{4}$ (7757-82-6, >99\%) were purchased from Shengao Chemical Industry, China. These reagents and dyes were directly used without any further purification. All solutions were prepared with ultrapure water (resistivity of $18.20 \mathrm{M} \Omega$ ). Graphite felt was purchased from Tianjin Carbon Factory, China, which was cut into $12 \times 1.5 \times 0.5 \mathrm{~cm}$ pieces. During the experiment, the graphite felt was immersed in water at a depth of $6 \mathrm{~cm}$. Graphite felt was washed with ultrapure water and then dried at $378.15 \mathrm{~K}$ for $24 \mathrm{~h}$.

\subsection{Reactor and degradation experiments}

Batch studies were performed in a columnar vessel (diameter of $90 \mathrm{~mm}$, height of $160 \mathrm{~mm}$ ). Then, $500 \mathrm{~mL}$ of $20 \mathrm{mg} \mathrm{L}^{-1}$ methylene blue solution was taken for every study. Both the electrodes (anode and cathode) were graphite felt with an effective area of $25 \mathrm{~cm}^{2}$. Continuous aeration to the cathode was performed using a fish aerator during the experiment. The graphite felt electrode was kept parallel and the spacing between plates was $4.0 \mathrm{~cm}$. The $\mathrm{pH}$ was adjusted using $0.1 \mathrm{M} \mathrm{H}_{2} \mathrm{SO}_{4} \cdot \mathrm{Na}_{2} \mathrm{SO}_{4}$ was used as the supporting electrolyte. A constant voltage was applied across the electrodes using a DC power supply. If no special instructions were given, all the voltages in the experiment are cell voltages. All experiments were conducted at room temperature $(293.15+2 \mathrm{~K})$.

\subsection{Analytical methods}

$\mathrm{H}_{2} \mathrm{O}_{2}$ and iron ions were sampled from the reactor every 5 minutes during the experiment. Methylene blue was sampled from the reactor every $1 \mathrm{~min}$ during the experiment. The concentration of $\mathrm{H}_{2} \mathrm{O}_{2}$ was analysed by a UV-vis spectrophotometer at $400 \mathrm{~nm}$ using the potassium titanium(Iv) oxalate method. ${ }^{25}$ The concentrations of total iron and $\mathrm{Fe}^{2+}$ were determined by the 1,10-phenanthroline spectrophotometric method $(\lambda=510 \mathrm{~nm}){ }^{26}{ }^{2}$ The $\mathrm{Fe}^{3+}$ was determined by subtraction of total iron minus $\mathrm{Fe}^{2+}$ concentrations. ${ }^{15}$ The methylene blue concentration at $664 \mathrm{~nm}$ was determined using an ultraviolet spectrophotometer. The ultraviolet spectrophotometer was purchased from HACH Company, Germany. Relative error of all experimental data was less than $1.5 \%$.

\subsection{Characterization of the GF}

The surface morphology was characterized by scanning electron microscopy (SEM, Hitachi S-470). The crystal structure of the catalysts was characterized via X-ray diffraction (XRD, Rigaku MiniFlex 600). The surface OGs were analyzed by X-ray photoelectron spectroscopy (XPS) analysis. XPS was obtained with an AXIS-Ultra electron spectrometer (Shimadzu, Japan). The specific surface area and pore volume were analyzed via $\mathrm{N}_{2}$ adsorption/desorption using the BET and $t$-plot method with a Novaeseries (Quantachrome Co., USA).

\subsection{Electric energy per order}

The EE/O can be calculated using eqn (5).

$$
\frac{\mathrm{EE}}{\mathrm{O}}=\frac{(P+U \times I) \times t}{V \times 60 \times \lg \left(\frac{C}{C_{0}}\right)}
$$

where eqn (5) represents the electric energy required in $\mathrm{kW}$ h to remove methyl blue by one order of magnitude in a unit volume ( $\mathrm{kW}$ h order of methyl blue $\mathrm{m}^{-3}$ ), $U$ is the voltage of DC power $(\mathrm{V}), P$ is the rated DC power $(\mathrm{W}), I$ is the current of DC power (A), and $t$ is the treatment time (min). $V$ is the volume of water treated at time $t(\mathrm{~L}), C_{0}$ is the initial concentration of methylene blue $\left(\mathrm{mg} \mathrm{L}^{-1}\right)$, and $C$ is the final concentration of methylene blue $\left(\mathrm{mg} \mathrm{L}^{-1}\right)$. 


\section{Results and discussion}

\subsection{Electrochemical generation of $\mathrm{H}_{2} \mathrm{O}_{2}$}

Compared with the traditional Fenton process, the E-Fenton process has the ability to produce $\mathrm{H}_{2} \mathrm{O}_{2}$ in situ; thus, the study of $\mathrm{H}_{2} \mathrm{O}_{2}$ generation is of great significance for understanding and regulation the E-Fenton process. The effect of $\mathrm{pH}$ and voltage on the yield of $\mathrm{H}_{2} \mathrm{O}_{2}$ was investigated in this study. We performed continuous aeration at the cathode using a fish aerator during the experiment. Since $\mathrm{Fe}^{2+}$ has a catalytic effect on $\mathrm{H}_{2} \mathrm{O}_{2}, \mathrm{Fe}^{2+}$ was not added. The catalytic effect of iron was lost, and the Fenton reaction stopped during the electrolysis. ${ }^{15}$ Fig. 1a showed that the yield of $\mathrm{H}_{2} \mathrm{O}_{2}$ decreased as the $\mathrm{pH}$ increased, which is consistent with the study of Lei Zhou et al. ${ }^{27}$ According to eqn (1), acid environment is a necessary condition for generating $\mathrm{H}_{2} \mathrm{O}_{2}$. The higher the $\mathrm{pH}$ value, the lower the concentration of $\mathrm{H}^{+}$in the solution. Therefore, as the $\mathrm{pH}$ increased, the yield of $\mathrm{H}_{2} \mathrm{O}_{2}$ gradually decreased. Fig. $1 \mathrm{~b}$ showed that as the voltage increased, the yield of $\mathrm{H}_{2} \mathrm{O}_{2}$ increased and then reached a maximum when the voltage was $7 \mathrm{~V}$. However, the yield decreased when the voltage was continuously increased to $9 \mathrm{~V}$. According to Faraday's law, the current density increases as the voltage increases, which leads to an increase in $\mathrm{H}_{2} \mathrm{O}_{2}$ yield. However, when the current intensity is too high, the oxidation rate of $\mathrm{H}_{2} \mathrm{O}_{2}$ will increase. $\mathrm{H}_{2} \mathrm{O}_{2}$ can be oxidized to $\cdot \mathrm{HO}_{2}$ and $\mathrm{H}^{+}$on the surface of the anode. $\cdot \mathrm{HO}_{2}$ is unstable and further decomposes into $\mathrm{H}^{+}$and $\mathrm{O}_{2}$ (eqn (6) and (7)). ${ }^{28,29}$ Safizadeh et al. suggested that excessive voltage will lead to the aggravation of the hydrogen evolution reaction (eqn (9)), and the hydrogen evolution reaction will reduce the concentration of $\mathrm{H}^{+}$per unit volume in solution. ${ }^{30}$ In addition, the reduction of $\mathrm{O}_{2}$ by a carbon electrode mainly occurs via 2 electrons or 4 electrons. ${ }^{31}$ The 2-electron reaction can produce $\mathrm{H}_{2} \mathrm{O}_{2}$ (eqn (1)), and the 4-electron reaction can produce $\mathrm{H}_{2} \mathrm{O}$ (eqn (8)). The 4electron side reaction will lead to a decrease in $\mathrm{H}_{2} \mathrm{O}_{2}$ yield under certain conditions of the solute.

After $20 \mathrm{~min}$ of reaction, the removal rates of methylene blue at voltages 3, 5, 7 and $9 \mathrm{~V}$ were $86.55 \%, 96.16 \%, 97.80 \%$ and $90.33 \%$, respectively. The highest removal rate of methylene blue was obtained at voltage $7 \mathrm{~V}$. This conclusion was consistent with the highest $\mathrm{H}_{2} \mathrm{O}_{2}$ yield at the voltage of $7 \mathrm{~V}$. Therefore, if the production of $\mathrm{H}_{2} \mathrm{O}_{2}$ can be further optimized, it is of great significance to improve the degradation rate of organic matter in the E-Fenton system. The removal rates of methylene blue at pH 2.5, 3, 3.5 and 4 were $97.73 \%, 97.80 \%, 94.92 \%$ and $93.87 \%$, respectively. Fig. 1a showed that when the $\mathrm{pH}$ was 2.5 , the yield of $\mathrm{H}_{2} \mathrm{O}_{2}$ was higher than at $\mathrm{pH} 3$. According to the calculation formula for $\mathrm{pH}$ (eqn (10)), the acid added at $\mathrm{pH} 2.5$ is $\sqrt{10}$ times the amount of the acid added at $\mathrm{pH} 3$, which considerably increases the amount of acid. According to Chen et al., the quenching effect of $\mathrm{H}^{+}$on the $\cdot \mathrm{OH}$ is more obvious under strong acid conditions. ${ }^{32}$ In addition, the reaction between $\mathrm{Fe}^{2+}$ and $\mathrm{H}_{2} \mathrm{O}_{2}$ will be inhibited. ${ }^{33}$ Therefore, $\mathrm{pH} 3$ was the optimal $\mathrm{pH}$ for methylene blue degradation in this experiment.

$$
\begin{gathered}
\mathrm{H}_{2} \mathrm{O}_{2} \rightarrow \cdot \mathrm{HO}_{2}+\mathrm{H}^{+}+\mathrm{e}^{-} \\
\cdot \mathrm{HO}_{2} \rightarrow \mathrm{O}_{2}+\mathrm{H}^{+}+\mathrm{e}^{-} \\
\mathrm{O}_{2}+4 \mathrm{H}^{+}+4 \mathrm{e}^{-} \rightarrow 2 \mathrm{H}_{2} \mathrm{O} \\
\mathrm{O}_{2}+4 \mathrm{H}^{+}+4 \mathrm{e}^{-} \rightarrow 2 \mathrm{H}_{2} \uparrow \\
\mathrm{pH}=-\lg C\left(\mathrm{H}^{+}\right)
\end{gathered}
$$

\subsection{Evolution of iron ions}

In the E-Fenton process, $\mathrm{Fe}^{3+}$ can be electronically reduced to $\mathrm{Fe}^{2+}$ at the cathode to achieve the cycle of $\mathrm{Fe}^{2+}$ and $\mathrm{Fe}^{3+}$, which considerably reduces the dosage of $\mathrm{Fe}^{2+}$ and the production of iron sludge. Therefore, the evolution of iron ions in this experiment was investigated. When the water contains dissolved oxygen, the $\mathrm{H}_{2} \mathrm{O}_{2}$ produced by the cathode will react with $\mathrm{Fe}^{2+}$. Thus, we adopted the method of continuous bubbling $\mathrm{N}_{2}$ by Aboudalle et al. during the experiment to remove the dissolved oxygen in the water. ${ }^{34}$ Fig. 2 a showed the total iron concentration did not remain constant when the $\mathrm{Fe}^{3+}$ was added to the solution. The total iron ions in the
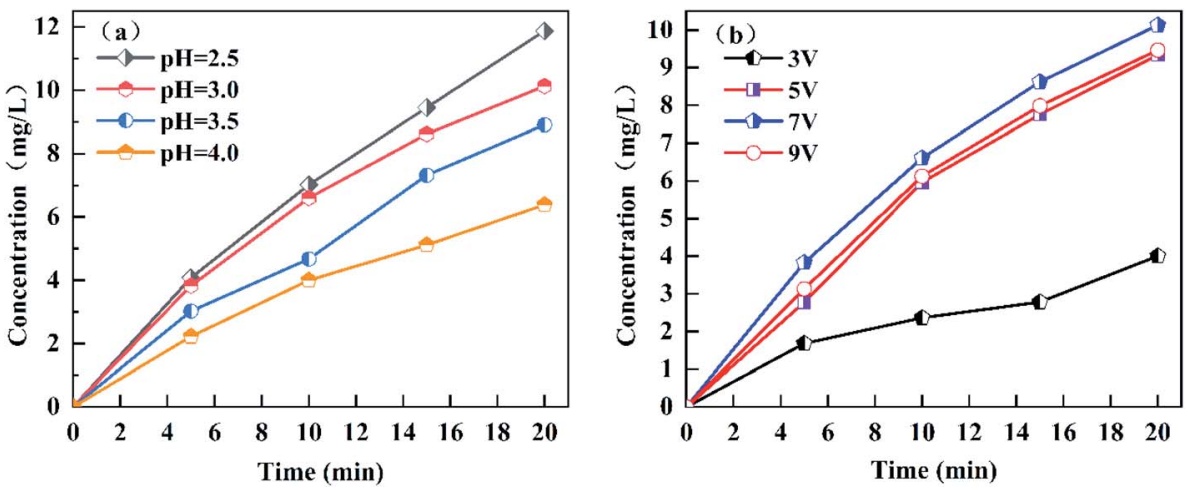

Fig. 1 Electrochemical generation of $\mathrm{H}_{2} \mathrm{O}_{2}$. Experimental conditions: $\mathrm{pH}=3$, voltage $=7 \mathrm{~V},\left[\mathrm{Na}_{2} \mathrm{SO}_{4}\right]=10 \mathrm{mmol} \mathrm{L}^{-1}$. (a) Effect of $\mathrm{pH}$ on the yield of $\mathrm{H}_{2} \mathrm{O}_{2}$. Experimental conditions: voltage $=7.0$, $\left[\mathrm{Na}_{2} \mathrm{SO}_{4}\right]=10 \mathrm{mmol} \mathrm{L}^{-1}$. (b) Effect of voltage on the yield of $\mathrm{H}_{2} \mathrm{O}_{2}$. Experimental conditions: $\mathrm{pH}$ $=3,\left[\mathrm{Na}_{2} \mathrm{SO}_{4}\right]=10 \mathrm{mmol} \mathrm{L}^{-1}$. 
solution gradually decreased, and the $\mathrm{Fe}^{2+}$ concentration gradually increased as the reaction proceeded (Fig. 2a and b). When electrolysed for $20 \mathrm{~min}$ at voltages of 3, 5, 7 and $9 \mathrm{~V}$, the total iron ions decreased by $0.91 \%, 8.55 \%, 12.43 \%$, and $19.33 \%$, respectively. Therefore, the higher the voltage, the more the total iron ion concentration decreases. The effect of voltage on the iron ions may be related to the variation in $\mathrm{pH}$. According to previous studies, when adding $1 \mathrm{mmol} \mathrm{L}^{-1} \mathrm{Fe}^{3+}$ to solution, $\left[\mathrm{Fe}\left(\mathrm{H}_{2} \mathrm{O}\right)_{6}\right]^{3+}$ or simply $\mathrm{Fe}^{3+}$ as the sole species at $\mathrm{pH} 0, \mathrm{Fe}^{3+}$ practically disappears at $\mathrm{pH} 4$. At the optimum $\mathrm{pH}$ of 2.8 , only approximately one-half of the free $\mathrm{Fe}^{3+}$ is always present in the bulk. ${ }^{22}$ In this experiment, with an increase in voltage, the cathode localized alkalization affected the $\mathrm{pH}$ near the cathode, ${ }^{22,35}$ which caused the total iron ion concentration to gradually decrease. Fig. $2 c$ showed that the rate of regeneration of $\mathrm{Fe}^{2+}$ first increased and then decreased with an increase in voltage. Although the total iron ion concentration was the highest at a voltage of $5 \mathrm{~V}$, the rate of $\mathrm{Fe}^{3+}$ reduction was faster because of the higher current density at the voltage of $7 \mathrm{~V}$. Thus, there was little difference in the $\mathrm{Fe}^{2+}$ regeneration rate at voltage $5 \mathrm{~V}$ and $7 \mathrm{~V}$ (76.75\% and $73.33 \%$, respectively). When the voltage was $3 \mathrm{~V}$, the cathode localized alkalization was not significant; thus, the total iron ion concentration was almost constant in solution. However, the regeneration rate of $\mathrm{Fe}^{2+}$ was only $60.19 \%$ due to a lower current density. When the voltage was $9 \mathrm{~V}$, the current density was large. Thus, the regeneration rate of $\mathrm{Fe}^{2+}$ at the early stage was higher than $3 \mathrm{~V}$. However, the total iron ion concentration sharply decreased with the reaction, resulting in a regeneration rate of $\mathrm{Fe}^{2+}$ of only $61.33 \%$.

Fig. $2 \mathrm{a}$ and $\mathrm{b}$ showed the ability of $\mathrm{Fe}^{3+}$ to regenerate $\mathrm{Fe}^{2+}$ under anaerobic conditions, whereas according to eqn (1) and (4), the regeneration and consumption of $\mathrm{Fe}^{2+}$ are simultaneous during the actual reaction. Therefore, the evolution of iron ions was studied during the degradation process of methylene blue in the graphite felt E-Fenton system, and the reaction time was extended to $90 \mathrm{~min}$; the results are shown in Fig. 2 d. As the reaction proceeded, the total iron ion concentration continued to decreased in the solution, which was consistent with the conclusions shown in Fig. 2a. However, when electrolysis was conducted for $20 \mathrm{~min}$, the total iron ion concentration dropped to $25.33 \%$, which was twice as much as under anaerobic conditions (12.43\%). The electrode localized alkalization was very
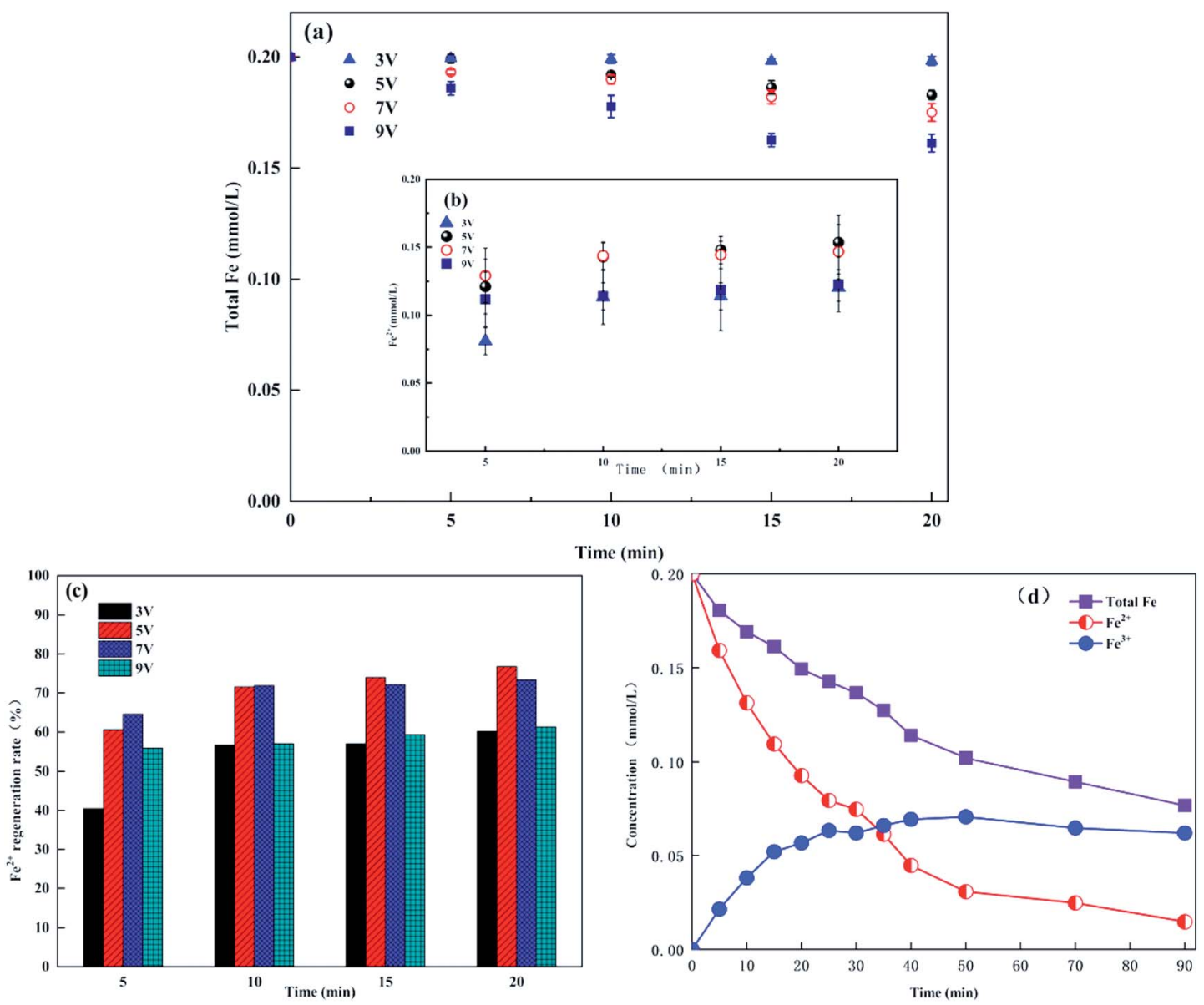

Fig. 2 Evolution of iron ions. (a) Effect of voltage on the total iron ion concentration. (b) Regeneration of Fe ${ }^{2+}$. (c) Regeneration rate of Fe $\mathrm{Re}^{2+}$. Experimental conditions: $\mathrm{Fe}^{3+}=0.2 \mathrm{mmol} \mathrm{L}^{-1}, \mathrm{pH}=3,\left[\mathrm{Na}_{2} \mathrm{SO}_{4}\right]=10 \mathrm{mmol} \mathrm{L}{ }^{-1}$. (d) Evolution of iron ions during the actual reaction. Experimental conditions: $\mathrm{Fe}^{2+}=0.2 \mathrm{mmol} \mathrm{L}-1$, voltage $=7.0, \mathrm{pH}=3,\left[\mathrm{Na}_{2} \mathrm{SO}_{4}\right]=10 \mathrm{mmol} \mathrm{L}^{-1}$. 
significant in the actual treatment process. During the actual treatment process, $\mathrm{O}_{2}$ continuously consumed $\mathrm{H}^{+}$at the cathode to produce $\mathrm{H}_{2} \mathrm{O}_{2}$, and $\mathrm{Fe}^{2+}$ reacted with $\mathrm{H}_{2} \mathrm{O}_{2}$ to generate $\mathrm{OH}^{-}$(eqn (1) and (2)). The local alkalization of the electrodes caused by these reactions was more pronounced, resulting in a final decrease in total iron concentration. In addition, $\mathrm{Fe}^{2+}$ can not maintain a stable concentration during the entire reaction process. The $\mathrm{Fe}^{2+}$ concentration gradually decreased with the electrolysis time, and the $\mathrm{Fe}^{3+}$ concentration gradually increased. This phenomenon was consistent with the research of Ramirez-Pereda et al., which showed that the regeneration rate of $\mathrm{Fe}^{2+}$ was lower than its consumption rate during the actual electrolysis process. ${ }^{\mathbf{1 5}}$

\subsection{Reaction kinetics of degradation of methylene blue by the electro-Fenton process}

Methylene blue $\left(20 \mathrm{mg} \mathrm{L}^{-1}\right)$ was degraded at a voltage of $7 \mathrm{~V}$ with $\mathrm{Fe}^{2+}$ at $0.2 \mathrm{mmol} \mathrm{L}{ }^{-1}$, the supporting electrolyte, $\mathrm{Na}_{2} \mathrm{SO}_{4}$, at $10 \mathrm{mmol} \mathrm{L}^{-1}$ and at $\mathrm{pH} 3$. The removal rate of methylene blue was $97.80 \%$ after 20 min of electrolysis. The E-Fenton oxidation of methylene blue can be represented by the following $n$ th-order reaction kinetics.

$$
\frac{\mathrm{d} C}{\mathrm{~d} t}=-k C^{n}
$$

where $C$ represents the dye concentration, $t$ represents the time, $k$ represents the reaction rate coefficient and $n$ represents the order of the reaction.

For the first order reaction, eqn (11) was integrated and converted:

$$
C_{t}=C_{0} \mathrm{e}^{-k t}
$$

in which $C_{0}$ is the initial dye concentration. For the second order reaction, eqn (11) was integrated and converted:

$$
C_{t}=\frac{C_{0}}{1+K C_{0} t}
$$

The degradation data of methylene blue in the graphite felt E-Fenton system was plotted via first-order reaction kinetics and second-order reaction kinetics. Fig. 3 showed a comparison of the two kinetic models for the experimental results, and Table 1 shows the parameters obtained from the curve fitting. The second-order kinetics does not fit the data very well for the entire E-Fenton reaction due to the lower regression coefficients $(<0.96)$. The first-order kinetics fits the results best as evidenced by the high regression coefficient $(>0.99)$. Therefore, the kinetics process of degradation of methylene blue by the graphite felt E-Fenton method was determined to be first-order reaction kinetics.

Its kinetic equation is:

$$
C_{t}=20 \mathrm{e}^{-0.26}
$$

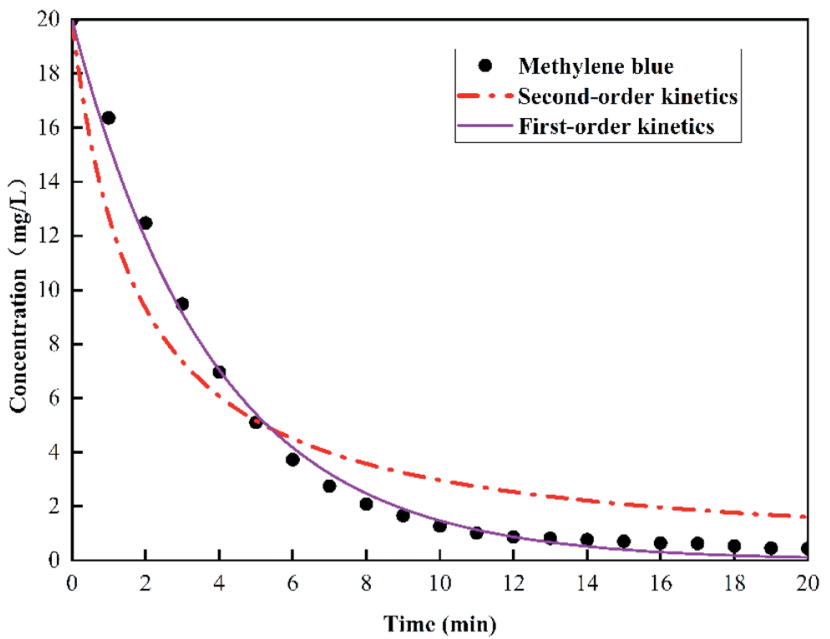

Fig. 3 Reaction kinetics of methylene blue degradation.

\subsection{Removal mechanism of the electro-Fenton system}

When methylene blue was degraded, its degradation rate decreased significantly after $\mathbf{1 5}$ minutes. In order to reduce the experimental error and to more clearly see the experimental differences under each reaction condition, the electrolysis time was set to 15 min during the investigation of degradation mechanism. Each set of experiments was repeated 3 times, and the average value was obtained.

Fig. $4 \mathrm{H}$ showed the individual adsorption effect of graphite felt on the removal rate of methylene blue, which was $3.26 \%$ after 15 min of adsorption. In addition, when $\mathrm{H}_{2} \mathrm{O}_{2}$ was added alone, methylene blue exhibited almost no degradation; thus, $\mathrm{H}_{2} \mathrm{O}_{2}$ cannot oxidize methylene blue alone without an electric field. Fig. 4A and $\mathrm{E}$ showed the degradation rate of methylene under the conditions of $\mathrm{Fe}^{2+}$ at $0.2 \mathrm{mmol} \mathrm{L}^{-1}$ and $0 \mathrm{mmol} \mathrm{L}^{-1}$, respectively. When $\mathrm{Fe}^{2+}$ was added to the solution, the removal rate of methylene blue increased by $41.37 \%$; thus, the Fenton reaction to produce $\cdot \mathrm{OH}$ and $\cdot \mathrm{HO}_{2}$ was the main factor for the degradation of methylene blue. Methanol is recognized as $\cdot \mathrm{OH}$ scavenger. The reaction rate of methanol with $\cdot \mathrm{OH}$ is $1.2 \times 10^{9}$ to $2.8 \times 10^{9} \mathrm{M}^{-1} \mathrm{~s}^{-1} \cdot{ }^{36}$ In the presence of $\mathrm{Fe}^{2+}, 5 \mathrm{~mL}$ of methanol was added to the solution. The removal rate of methylene blue decreased by $52.33 \%$, which confirmed that $\cdot \mathrm{OH}$ was the main active substance in the E-Fenton system (Fig. 4A and F). When $5 \mathrm{~mL}$ of methanol was added without the $\mathrm{Fe}^{2+}$-forming Fenton reagent in the solution, the removal rate of methylene blue did not significantly change (Fig. 4C and E). This showed that the methylene blue is directly oxidized by the graphite felt anode.

Table 1 Kinetic parameters for E-Fenton oxidations of methylene blue

\begin{tabular}{llllll}
\hline & \multicolumn{2}{l}{ First-order } & & & \multicolumn{2}{l}{ Second-order } \\
\cline { 2 - 3 } \cline { 5 - 6 } Reaction & $K\left(\mathrm{~min}^{-1}\right)$ & $R^{2}$ & & $K\left(\mathrm{~L} \mathrm{mg}^{-1} \mathrm{~min}\right)$ & $R^{2}$ \\
\hline E-Fenton & 0.26 & 0.995 & 0.03 & 0.911
\end{tabular}




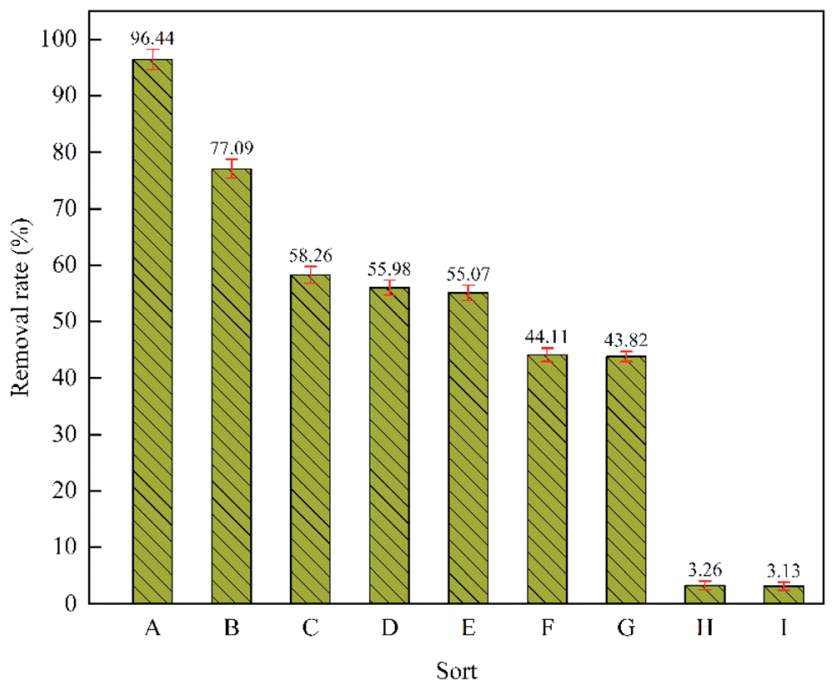

Fig. 4 Inhibition experiments under different experimental conditions. Experimental conditions: methylene blue $=20 \mathrm{mg} \mathrm{L}^{-1}, \mathrm{pH}=3$, voltage $=7 \mathrm{~V},\left[\mathrm{Na}_{2} \mathrm{SO}_{4}\right]=10 \mathrm{mmol} \mathrm{L}^{-1}$. (A) Electrolysis with aeration $\left(\mathrm{O}_{2}\right), \mathrm{Fe}^{2+}$ $=0.2 \mathrm{mmol} \mathrm{L}^{-1}$. (B) Electrolysis without aeration, $\mathrm{Fe}^{2+}=0.2 \mathrm{mmol} \mathrm{L}^{-1}$ (C) Electrolysis with aeration $\left(\mathrm{O}_{2}\right), \mathrm{Fe}^{2+}=0 \mathrm{mmol} \mathrm{L}{ }^{-1}$, methanol $=5$ $\mathrm{mL}$. (D) Electrolysis with aeration $\left(\mathrm{N}_{2}\right), \mathrm{Fe}^{2+}=0 \mathrm{mmol} \mathrm{L}^{-1}$. (E) Electrolysis with aeration $\left(\mathrm{O}_{2}\right), \mathrm{Fe}^{2+}=0 \mathrm{mmol} \mathrm{L}^{-1}$. (F) Electrolysis with aeration $\left(\mathrm{O}_{2}\right), \mathrm{Fe}^{2+}=0.2 \mathrm{mmol} \mathrm{L}{ }^{-1}$, methanol $=5 \mathrm{~mL}$. (G) Electrolysis with aeration $\left(\mathrm{O}_{2}\right), \mathrm{Fe}^{2+}=0 \mathrm{mmol} \mathrm{L}-1,\left[\mathrm{H}_{2} \mathrm{O}_{2}\right]=10 \mathrm{~mL}$. (H) Graphite felt electrode adsorption alone. (I) Electrolysis without aeration, $\mathrm{Fe}^{2+}=$ $0 \mathrm{mmol} \mathrm{L}^{-1}$.

According to Fig. $4 \mathrm{E}$ and $\mathrm{G}$, the removal rate of methylene blue decreased when $10 \mathrm{~mL}$ of $\mathrm{H}_{2} \mathrm{O}_{2}$ was added to the solution; thus, $\mathrm{H}_{2} \mathrm{O}_{2}$ cannot produce $\cdot \mathrm{OH}$ under the action of an electric field without $\mathrm{Fe}^{2+}$. In contrast, the competition between $\mathrm{H}_{2} \mathrm{O}_{2}$ anodic oxidation and methylene blue anodic oxidation resulted in a decrease in the removal rate of methylene blue.

In addition, aeration had a significant effect on the degradation of methylene blue in the graphite felt E-Fenton system. When the solution did not contain $\mathrm{Fe}^{2+}$, the removal rate was $3.13 \%$ and $55.07 \%$ under conditions of no aeration and aeration, respectively (Fig. 4E and I). When the solution contained $\mathrm{Fe}^{2+}$, the removal rate was $77.09 \%$ and $96.44 \%$ under conditions of no aeration and aeration, respectively (Fig. 4A and B). Tammeveski et al. thought that because an activated carbon fibre surface contains a large number of functional groups, $\mathrm{O}_{2}$ will be reduced to $\cdot \mathrm{O}_{2}{ }^{-}$at the cathode. ${ }^{37}$ Based on this, we speculate that aeration may play three roles in the graphite felt E-Fenton system: (i) as active substance, where $\cdot \mathrm{O}_{2}{ }^{-}$was produced under the action of an electric field; (ii) to accelerate the mass transfer of the solutions; (iii) and to produce the Fenton reagent, $\mathrm{H}_{2} \mathrm{O}_{2}$, at the cathode. According to Fig. $4 \mathrm{D}$ and $\mathrm{E}$, when $\mathrm{N}_{2}$ or $\mathrm{O}_{2}$ was exposed to the solution without $\mathrm{Fe}^{2+}$, the removal rate of methylene blue did not significantly change; thus, it can be concluded that no $\cdot \mathrm{O}_{2}{ }^{-}$was produced. When $\mathrm{Fe}^{2+}$ was not present in this system, the main role of $\mathrm{O}_{2}$ was to accelerate the mass transfer. When $\mathrm{Fe}^{2+}$ was present, the role of $\mathrm{O}_{2}$ was to accelerate the solution mass transfer and the generation of the Fenton reagent, $\mathrm{H}_{2} \mathrm{O}_{2}$. When $\mathrm{Fe}^{2+}$ was present and the solution was not aerated, the potential difference between the anode and the cathode was the migration power of the ions. $\mathrm{Fe}^{2+}$ and $\mathrm{H}^{+}$ migrated to the cathode and generated $\cdot \mathrm{OH}$ via eqn (1) and (2). In addition, methylene blue formed a highly chromatic monovalent cationic quaternary ammonium salt ionic group in aqueous solution, and the quaternary ammonium salt ionic group migrated to the cathode under the action of an electric field, which accelerated the reaction rate of methylene blue with - $\mathrm{OH}$. Therefore, there was a high degradation rate of methylene blue even under the condition of no aeration. When no $\mathrm{Fe}^{2+}$ was in the solution, the degradation of methylene blue depended on the direct oxidation of the anode; however, the anode will repel methylene blue because of the charged nature of methylene blue. Therefore, the degradation of methylene blue was very slow under unaerated conditions. When continuous aeration was applied to the solution, the disturbance of oxygen on water overcomes the repulsive force of the anode on methylene blue and enabled methylene to be oxidized directly at the anode.

In summary, a probable mechanism of the graphite felt EFenton system to remove the methylene blue is shown in Fig. 5. During the electrolysis process, the graphite felt anode can directly oxidize the methylene blue. $\mathrm{H}_{2} \mathrm{O}_{2}$ was electrogenerated from the reduction of $\mathrm{O}_{2}$ on the graphite felt cathode under the condition of aeration. $\mathrm{H}_{2} \mathrm{O}_{2}$ then migrated into the liquid phase to react with $\mathrm{Fe}^{2+}$ and $\mathrm{Fe}^{3+}$. The $\cdot \mathrm{OH}$ and $\cdot \mathrm{HO}_{2}$ were generated by the Fenton and Fenton-like reaction. Then, the methylene blue was degraded by $\cdot \mathrm{OH}$ and $\cdot \mathrm{HO}_{2}$ indirectly.

\subsection{Repeated use of graphite felt in the E-Fenton system and cost analysis}

In order to study the stability of graphite felt electrode, the experiment of reusing was carried out. Fig. 6(a) showed the change in methylene blue removal rate and system current with the number of uses under the optimal conditions for $15 \mathrm{~min}$ of electrolysis. The graphite felt electrode was not regenerated during the process of repeated use. According to Fig. 6(a), the methylene blue removal rate and current showed a downward trend with increasing usage counts. After 90 times of repeated

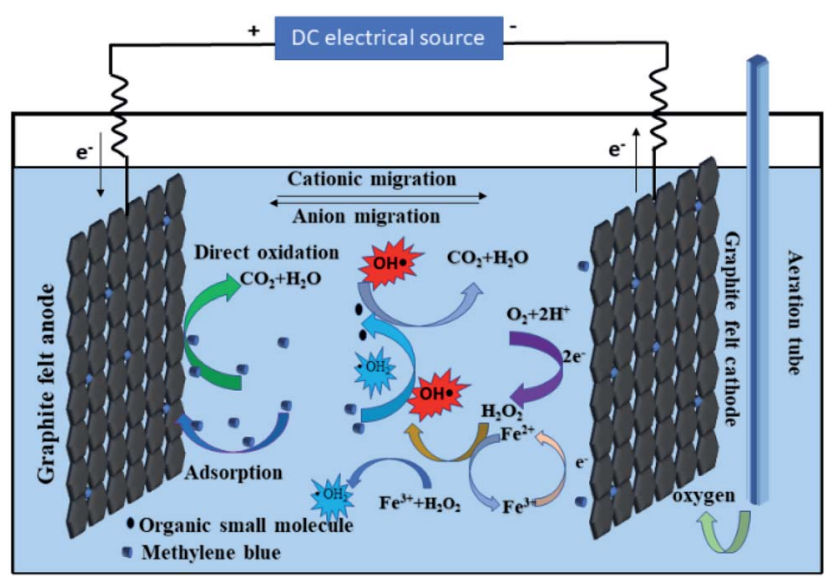

Fig. 5 Degradation mechanism of the graphite felt E-Fenton system. 

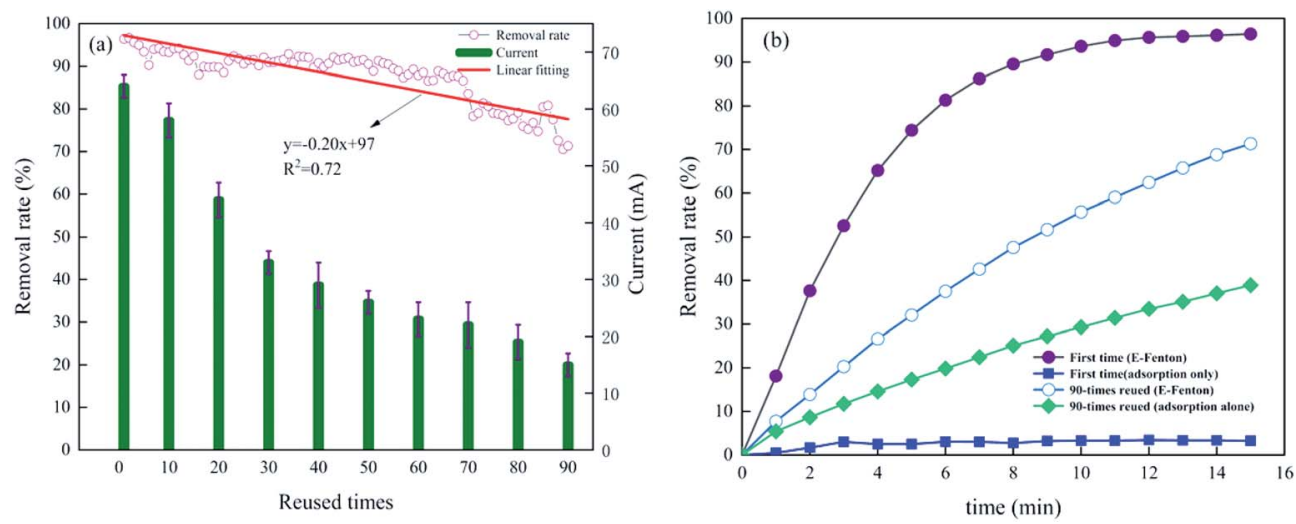

Fig. 6 Repeated use of graphite felt in the E-Fenton system. (a) Changes in methylene blue removal rate and system current. (b) Comparison of removal rate and adsorption performance.

use, the removal rate decreased by $26.02 \%$, and the current decreased by $76.56 \%$. Linear fitting was performed on the change of methylene blue removal rate, and the slope of the fitting line was -0.20 . The removal rate of graphite felt only decreased by $0.20 \%$ for each use, which reflected the good reusable performance of graphite felt. In addition, the current drop was much larger than the removal rate during the reusing process. According to Fig. 6(b), the adsorption performance of graphite felt was greatly improved after repeated use. The adsorption removal rate of unused graphite felt to the methylene blue was only $3.26 \%$. After 90 repeated times of use, the adsorption removal rate of graphite felt to the methylene blue was $38.91 \%$, and the adsorption effect was considerably improved. Although the current density of the E-Fenton system decreased during repeated use, the increase in the adsorption capacity was helpful to shorten the reaction path between methylene blue and active substances, which made up for repeated use current greatly reduced defects to some extent.

This study initially investigated the reasons for the decrease of current and removal rate during the repeated use of graphite felt E-Fenton system. According to eqn (15), under the condition of constant voltage and constant solution composition, the reason for the decrease in current was the increase in the internal resistance of the graphite felt electrode.

$$
I=\frac{U}{R_{\mathrm{e}}+R_{\mathrm{i}}}
$$

where $I$ represents the current $(\mathrm{mA}), U$ represents the voltage (V), $R_{\mathrm{i}}$ represents the internal resistance of the graphite felt electrode, and $R_{\mathrm{e}}$ represents the external resistance of the solution.

We used the original graphite felt $\mathrm{A}$, the repeated use graphite felt $\mathrm{B}$ (used as the anode) and the repeated use graphite felt $\mathrm{C}$ (used as the cathode) and completed a total of 7 permutation combinations to study the reasons for the decrease in current and removal rate (Table 2). The experimental results were shown in Fig. 7(a) and (b).

According to Fig. 7(a), the current of the A+A system was 64 $\mathrm{mA}$; however, the currents of the A + B, B + A, C + B, and B + C systems were $25,18,13$, and $15 \mathrm{~mA}$, respectively. These results indicated that in the presence of the B electrode, the current value of the entire E-Fenton system is low regardless of whether the B electrode continues to function as the anode or the cathode, or whether the counter electrode or the new electrode is used. The currents of the A+ C and C + A system were $55 \mathrm{~mA}$ and $67 \mathrm{~mA}$, respectively, indicating that the repeated use cathode $\mathrm{C}$ has little influence on the current drop. Thus, the decrease in current was because of the increase in anode resistance.

Fig. 7(b) showed the first-order linear fitting results for methylene blue removal. The $K$ values (the reaction rate coefficients) of the $\mathrm{A}+\mathrm{A}, \mathrm{C}+\mathrm{A}, \mathrm{A}+\mathrm{C}, \mathrm{B}+\mathrm{A}, \mathrm{B}+\mathrm{C}, \mathrm{A}+\mathrm{B}$, and $\mathrm{C}+\mathrm{B}$ systems were $0.22,0.19,0.14,0.11,0.08,0.07$, and $0.06 \mathrm{~min}^{-1}$, respectively. Upon comparing the $K$ value of $\mathrm{B}+\mathrm{C}(0.08)$ with the B + A (0.11), A + B (0.07), and C + B (0.06) systems, the removal rate of methylene blue was very low regardless of how the electrode was replaced in the presence of electrode $\mathrm{B}$. Upon comparing B + C (0.08) with C + A (0.19) and A + C (0.14), the $K$ value increased as long as electrode $B$ was replaced. Thus, the decrease in catalytic activity of electrode B was the main reason for the decrease in the methylene blue removal rate.

Although the catalytic activity of electrode $\mathrm{C}$ is lowered, the magnitude of the decrease was much smaller than the decrease of the electrode B. Therefore, the method of replacing the anode $\mathrm{B}$ can be used to restore the degradation efficiency of the EFenton system in practical application. However, it did not work well to only use the new electrode A to replace the used anode $\mathrm{B}$ (the $K$ value of $\mathrm{A}+\mathrm{C}$ was 0.14$)$. According to $\mathrm{C}+\mathrm{A}(0.19)$ and $\mathrm{A}+\mathrm{C}(0.14)$, the new electrode $\mathrm{A}$ was used to replace electrode $\mathrm{C}$ as a cathode, and electrode $\mathrm{C}$ was no longer used as a cathode but was used as an anode. This electrode replacement method can restore the maximum removal efficiency of the E-

Table 2 Different electrode combinations

Electrode Different electrode combinations

$\begin{array}{lllllllll}\text { Anode } & \text { A } & \text { A } & \text { A } & \text { B } & \text { B } & \text { C } & \text { C }\end{array}$

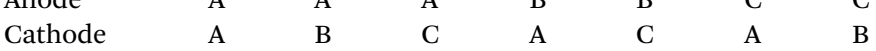



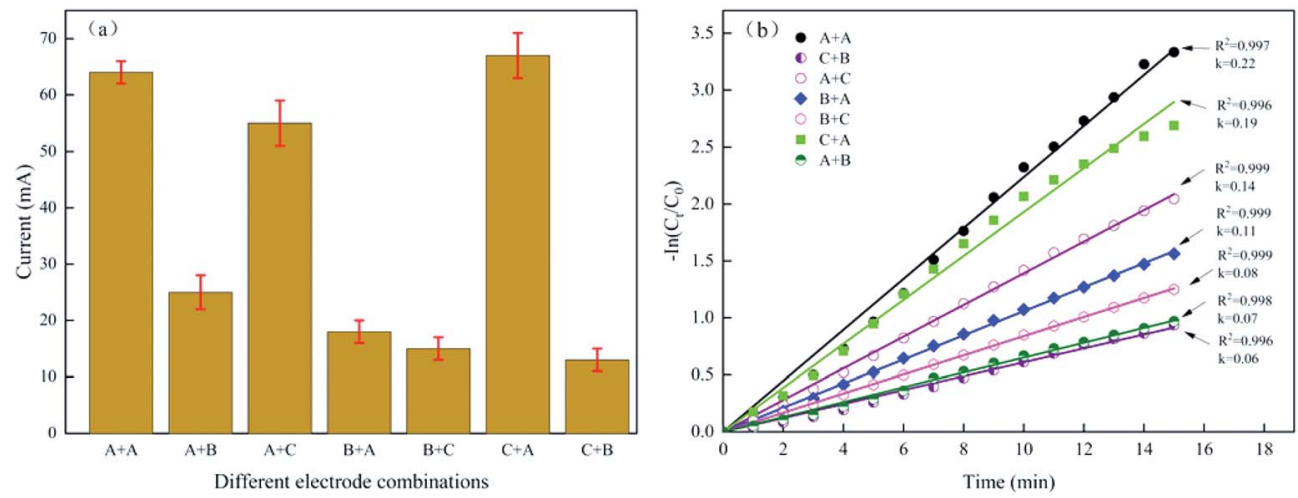

Fig. 7 Different electrode combinations. (a) Current of different electrode combinations. (b) First-order linear fitting results for methylene blue removal rate.

Fenton system, and the $K$ value is only 0.03 different from that of the new electrode system A + A.

It can be determined graphite felt will cause three changes after being used as anode: the conductivity and catalytic performance will be decreased, and the adsorption performance will be increased. According to the characterization results of Fig. 8, the reasons for the above performance changes can be preliminarily inferred. The pore width distribution showed the number of micropores increased. BET test showed the specific surface area of anode graphite felt increased by 3.69 $\mathrm{m}^{2} \mathrm{~g}^{-1}$ compared with the raw graphite felt. In addition, performance changes may be related to changes in crystal structure.$^{38}$ The XRD results showed that the diffraction peak at $2 \theta=23^{\circ}$ was stronger, corresponding to the (002) crystal plane of the graphite crystallite; the diffraction peak at $2 \theta=44^{\circ}$ was weaker, corresponding to the (010) crystal plane of the graphite crystallite, and the peak shape of the two diffraction peaks was wider, which proves that the graphite felt was a graphite microcrystalline layered structure. And the characteristic diffraction peak position of the anode did not change substantially, indicating that the graphite felt electrode did not change the graphite fiber structure before and after use. However, the intensity of the anode peak was weakened, the peak height was shortened, and the width was increased, indicating that the anode graphite felt grain becomes smaller, the delocalized electrons decreased, the grain boundary hindered the electron conduction, and the resistance increased. SEM image showed that the anode attachment increases, which may affect the conductivity. Moreover, cracks appeared in the structure of anode fiber, which indicated that the physical strength and mechanical strength of graphite felt were damaged greatly and the electrode life was reduced. The XPS
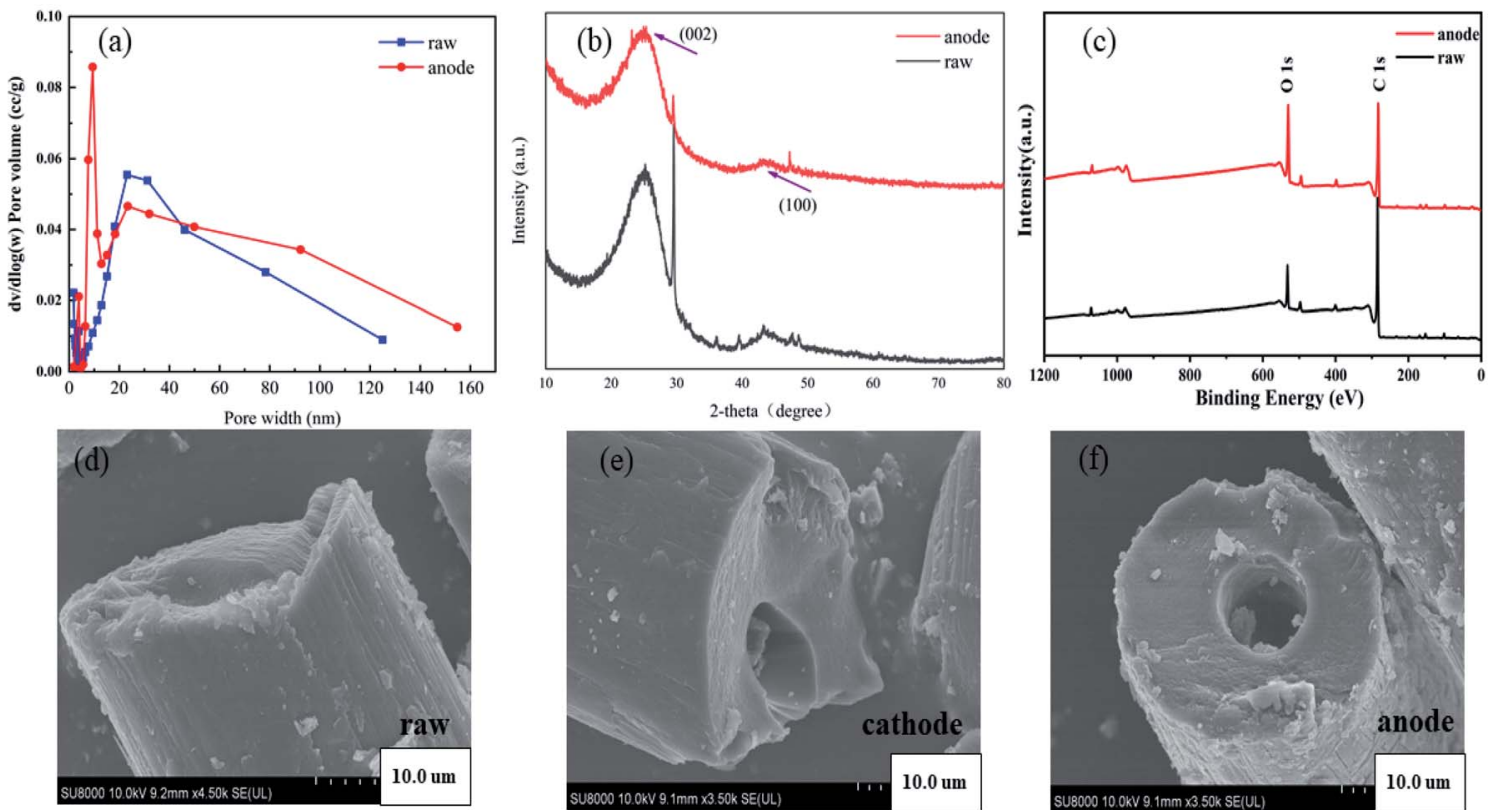

Fig. 8 (a) Pore width of raw GF and anode GF, (b) X-ray diffraction patterns of raw GF and anode GF, (c) XPS survey spectra of raw GF and anode GF. SEM images of (d) $-(\mathrm{f})$. 
results showed that the $\mathrm{O} 1 \mathrm{~s}$ peak was greatly enhanced, while the $\mathrm{C}$ element peak intensity was slightly lowered. The content of $\mathrm{C}=\mathrm{O}$ decreased from $47.12 \%$ to $40.31 \%$ and the content of $\mathrm{H}-\mathrm{O}-\mathrm{H}$ increased from $19.87 \%$ to $27.42 \%$. The decrease in electrical conductivity and catalytic performance may be related to changes in oxygen-containing functional groups. ${ }^{13}$ Malitesta et al. indicated the oxygen can be located not only at the beta carbon but also on the alpha carbon, leading to the breakage of polymer chains, resulting in a decrease in conductivity. ${ }^{39}$

In this study, the removal rate of methylene blue was $97.80 \%$ after electrolysis for $20 \mathrm{~min}$ in the graphite felt E-Fenton system, and these results were very competitive if compared with the traditional graphite electrode system. ${ }^{16}$ Electric energy consumption is a key index to evaluate the scale-up and industrial applications of the graphite felt E-Fenton system. In this study, the voltage and current of the DC power were $7 \mathrm{~V}$ and $64 \mathrm{~mA}$, respectively. The rated power of the fish aerator was $1 \mathrm{~W}$. $C_{0}$ and $C$ were $20 \mathrm{mg} \mathrm{L}^{-1}$ and $0.44 \mathrm{mg} \mathrm{L}^{-1}$, respectively. The volume of water treated was $0.5 \mathrm{~L}$, and the electrolysis time was 20 min. Taking the above data into eqn (5), the EE/O of the graphite felt system was calculated, and the results were 0.55 $\mathrm{kW} \mathrm{h} \mathrm{m}{ }^{-3}$, which revealed a significant reduction in energy consumption. ${ }^{15}$ The graphite felt also showed a good price advantage. The price of graphite felt purchased by our laboratory was 35 yuan $(20 \times 123 \times 0.5 \mathrm{~cm}$ pieces $)$. After cutting it into electrodes $(12 \times 1.5 \times 0.5 \mathrm{~cm}$ pieces $)$, each graphite felt electrode was only approximately 0.3 Yuan. Moreover, the adsorption performance of the graphite felt used in the E-Fenton system was considerably improved; therefore, the anode graphite felt can be used alone as an adsorbent. In general, the graphite felt E-Fenton system has a good practical significance.

\section{Conclusion}

Graphite felt was used as the anode and cathode to investigate the application performance in the E-Fenton system. $\mathrm{pH}$ and voltage affected the yield of $\mathrm{H}_{2} \mathrm{O}_{2}$. The yield of $\mathrm{H}_{2} \mathrm{O}_{2}$ decreased as $\mathrm{pH}$ increased and first increased and then decreased as voltage increase. Voltage affected the evolution of iron ions. The higher the voltage, the faster the total iron concentration decreased. The regeneration rate of $\mathrm{Fe}^{2+}$ can reach $73.33 \%$ under the condition of $\mathrm{N}_{2}$ aeration at a voltage of $7 \mathrm{~V}$ and $\mathrm{pH} 3$. The graphite felt E-Fenton system can effectively remove the methylene blue. At a voltage of $7 \mathrm{~V}, \mathrm{pH} 3$ and a supporting electrolyte of $10 \mathrm{mmol} \mathrm{L}^{-1} \mathrm{Na}_{2} \mathrm{SO}_{4}$, the removal rate of methylene blue was $97.80 \%$ after 20 min of electrolysis. The reaction kinetics of the degradation of methylene blue from the EFenton system was fitted. The degradation of methylene blue is consistent with the first-order reaction kinetics, and its kinetic equation is: $C_{t}=20 \mathrm{e}^{-0.26}$. The mechanism of degradation of methylene blue by the graphite felt E-Fenton system was discussed. In addition to the indirect oxidation of $\cdot \mathrm{HO}_{2}$ and $\cdot \mathrm{OH}$, this also includes direct oxidation of the anode and adsorption of the graphite felt. The graphite felt E-Fenton system was used repeatedly 90 times, and the results showed that the removal rate of graphite felt only decreased by $0.20 \%$ for each use, which reflected the good reusable performance of graphite felt. Graphite felt exhibited a greatly enhanced adsorption performance after repeated use and can be used as a good adsorbent. The decrease in catalytic activity of electrode $\mathrm{B}$ was the main reason for the decrease in the methylene blue removal rate. A method of replacing the electrode was proposed, which could restore the removal efficiency of the E-Fenton system to the greatest extent, and the $K$ value was only 0.03 different from the new electrode system A. The cost analysis showed that the graphite felt E-Fenton system has the potential for scale-up and industrial application.

\section{Conflicts of interest}

There are no conflicts to declare.

\section{Acknowledgements}

The financial support from the National Natural Science Foundation of China (U1803244) is gratefully acknowledged.

\section{References}

1 I. Sirés, E. Brillas, M. A. Oturan, M. A. Rodrigo and M. Panizza, Environ. Sci. Pollut. Res. Int., 2014, 21, 8336.

2 E. J. Ruiz, A. Hernández-Ramírez, J. M. Peralta-Hernández, C. Arias and E. Brillas, Chem. Eng. J., 2011, 171, 385-392.

3 I. Oller, S. Malato and J. A. Sánchez-Pérez, Sci. Total Environ., 2011, 409, 4141-4166.

4 F. Sopaj, N. Oturan, J. Pinson, F. Podvorica and M. A. Oturan, Appl. Catal., B, 2016, 199, 331-341.

5 N. Barhoumi, N. Oturan, H. Olvera-Vargas, E. Brillas, A. Gadri, S. Ammar and M. A. Oturan, Water Res., 2016, 94, $52-61$.

6 T. X. H. Le, R. Esmilaire, M. Drobek, M. Bechelany, C. Vallicari, D. L. Nguyen, A. Julbe, S. Tingry and M. Cretin, J. Mater. Chem. A, 2016, 4, 17686-17693.

7 P. V. Nidheesh and R. Gandhimathi, Desalin. Water Treat., 2014, 52, 1872-1877.

8 E. Bocos, E. González-Romero, M. Pazos and M. A. Sanromán, Chem. Eng. J., 2016, 318, 19-28.

9 M. Munoz, Z. M. D. Pedro, J. A. Casas and J. J. Rodriguez, Appl. Catal., B, 2015, 176-177, 249-265.

10 Y. Zhang, Y. Wang and I. Angelidaki, J. Power Sources, 2015, 291, 108-116.

11 M. A. Fard and B. Barkdoll, Electrochim. Acta, 2018, 265, 209220.

12 T. Yatagai, Y. Ohkawa, D. Kubo and Y. Kawase, Environ. Lett., 2016, 52, 74-83.

13 W. Zhou, L. Rajic, X. X. Meng, R. Nazari, Y. W. Zhao, Y. Wang, J. H. Gao, Y. K. Qin and A. N. Alshawabkeh, Chem. Eng. J., 2019, 364, 428-439.

14 Y. Wang, W. Zhou, J. H. Gao, Y. N. Ding and K. K. Kou, J. Electroanal. Chem., 2019, 833, 258-268.

15 B. Ramirez-Pereda, A. Alvarez-Gallegos, J. G. Rangel-Peraza and Y. A. Bustos-Terrones, J. Environ. Manage., 2018, 213, 279-287. 
16 P. V. Nidheesh and R. Gandhimathi, Desalination, 2012, 299, 1-15.

17 S. C. Elaoud, M. Panizza, G. Cerisola and T. Mhiri, J. Electroanal. Chem., 2012, 667, 19-23.

18 T. X. H. Le, M. Bechelany and M. Cretin, Carbon, 2017, 122, 564-591.

19 A. Özcan, Y. Şahin, A. S. Koparal and M. A. Oturan, Appl. Catal., B, 2009, 89, 620-626.

20 C. Zhao, B. Si, Z. A. Mirza, Y. Liu, X. He, J. Li, Z. Wang and H. Zheng, Sep. Purif. Technol., 2017, 187, 397-406.

21 S. O. Ganiyu, T. X. H. Le, M. Bechelany, N. Oturan, S. Papirio, G. Esposito, E. van Hullebusch, M. Cretin and M. A. Oturan, Chem. Eng. J., 2018, 350, 844-855.

22 E. Brillas, I. Sirés and M. A. Oturan, Chem. Rev., 2009, 109, 6570.

23 F. Yi, S. Chen and C. Yuan, J. Hazard. Mater., 2008, 157, 7987.

24 L. Zhou, M. Zhou, C. Zhang, Y. Jiang, Z. Bi and J. Yang, Chem. Eng. J., 2013, 233, 185-192.

25 K. Sunil and B. Narayana, Bull. Environ. Contam. Toxicol., 2008, 81, 422-426.

26 J. E. Amonette, Clays Clay Miner., 1998, 46, 51-62.

27 L. Zhou, Z. Hu, C. Zhang, Z. Bi, T. Jin and M. Zhou, Sep. Purif. Technol., 2013, 111, 131-136.
28 C. A. Martínez-Huitle and E. Brillas, Appl. Catal., B, 2015, 166-167, 603-643.

29 M. Zarei, D. Salari, A. Niaei and A. Khataee, Electrochim. Acta, 2009, 54, 6651-6660.

30 F. Safizadeh, N. Sorour, E. Ghali and G. Houlachi, Int. J. Hydrogen Energy, 2017, 42, 5455-5463.

31 Y. Li, G. Zhong, H. Yu, H. Wang and F. Peng, Phys. Chem. Chem. Phys., 2015, 17, 21950-21959.

32 C. Chen, W. Zhao, J. Li, J. Zhao, H. Hidaka and N. Serpone, Environ. Sci. Technol., 2002, 36, 3604.

33 X. Liu, S. Yuan, M. Tong and D. Liu, Water Res., 2017, 113, 72-79.

34 A. Aboudalle, F. Fourcade, A. A. Assadi, L. Domergue, H. Djelal, T. Lendormi, S. Taha and A. Amrane, Chemosphere, 2018, 199, 486.

35 E. Petrucci, A. D. Pozzo and L. D. Palma, Chem. Eng. J., 2016, 283, 750-758.

36 G. V. Buxton, C. L. Greenstock, W. P. Helman and A. B. Ross, J. Phys. Chem. Ref. Data, 1988, 17, 513-886.

37 K. Tammeveski, K. Kontturi, R. J. Nichols, R. J. Potter and D. J. Schiffrin, J. Electroanal. Chem., 2001, 515, 101-112.

38 T. X. H. Le, C. Charmette, M. Bechelany and M. Cretin, Electrochim. Acta, 2016, 188, 378-384.

39 C. Malitesta, I. Losito, L. Sabbatini and P. G. Zambonin, J. Electron Spectrosc. Relat. Phenom., 1995, 76, 629-634. 